\title{
The effect of 10 weeks of strength training on the electromyographic response of quadriceps portions
}

\section{Efeito de 10 semanas de treinamento na resposta eletromiográfica das porções do quadríceps}

Frank Douglas Tourino ${ }^{1}$

(D) https://orcid.org/0000-0002-6513-3045

Lucas Túlio de Lacerda ${ }^{1}$

(D) https://orcid.org/0000-0002-0735-8131

André Gustavo Pereira de Andrade ${ }^{1}$

(D) https://orcid.org/0000-0003-3406-4558

Rodrigo César Ribeiro Diniz ${ }^{1}$

(D) https://orcid.org/0000-0001-9425-4447

Mauro Heleno Chagas ${ }^{1}$

(D) https://orcid.org/0000-0002-1955-8990

Fernando Vitor Lima ${ }^{1}$

(D) https://orcid.org/0000-0001-9293-7340

Abstract - This study investigate the effect of 10-week strenght training on the amplitude of the electromyographic (EMG) signal of vastus medialis, vastus lateralis and rectus Femoris. Twenty three untrained volunteers performed $3-5$ sets ( 3 sets - weeks 1 and 2; 4 series - weeks 3 and $4 ; 5$ series weeks 5 to 10) with 6 repetitions, intensity of $50 \%$ of 1 repetition maximum $(1 \mathrm{RM}), 3$ min rest between sets and $6 \mathrm{~s}$ repetition duration at the knee extensor exercise. One group (5:1) performed concentric action of $5 \mathrm{~s}$ and eccentric of $1 \mathrm{~s}$ and the other (3:3) performed concentric of $3 \mathrm{~s}$ and eccentric of $3 \mathrm{~s}$. The VM, VL and RF EMG (RMS) activities were recorded in each repetition of the three series at the first training session and the first three series at the last session. The protocol 5:1 led to EMG reduction in all portions, with a greater number of repetitions presenting differences at the VL and RF.VM and RF presented similar results at Group 3:3. It was verified that all the differences occurred in the second half of the series. It was also verified differences in EMG ratios just in group 3:3 and only in VM/ $\mathrm{VL}$ and VM/RF. These results suggest that the coordination was not affected when equivalent repetitions of series were compared. It was also suggested that these results were influenced by the reduced degrees of freedom of the exercise and the training load progression adopted.

Key words: Eletromyography; Muscle strength; Quadriceps.

Resumo - Este estudo investigou o efeito de 10 semanas de treinamento de força na resposta eletromiográfica (EMG) do vasto medial, vasto lateral e reto femoral. 23 voluntárias executaram 3 a 5 séries de 6 repetiçôes, intensidade de 50\% de 1 repetição máxima (RM), 3 minutos de pausa entre as séries e duração da repetição de $6 s$ no exercício extensor de joelhos. Um grupo (5:1) realizou a duração da ação concêntrica em 5 s e excêntrica em 1s e outro grupo (3:3) realizou a concêntrica em 3 s e a excêntrica em 3s. A atividades $E M G(R M S)$ destas três porçôes do quadriceps foram registradas em cada repetição das 3 séries da primeira sessão de treinamento e nas três primeiras séries da última sessão. Os resultados mostraram diferenças na metade final das séries, sendo que no grupo 5:1 houve redução na EMG em todas as porçôes e o VL e o RF mostraram redução em um número maior de repetiçôes. No grupo 3:3 o VM e o RF apresentaram redução. Para as relaçôes de ativação entre as porçôes, diferenças foram identificadas apenas no grupo 3:3 nas relaçôes $V M / V L$ e VM/RF em um número reduzido de repetiçôes. Estes resultados apontam que a coordenação entre as porções sofreu poucas alteraçōes quando comparadas as repetiçöes equivalentes de cada série. Sugere-se que os reduzidos graus de liberdade do movimento utilizado e a progressão da carga de treinamento tenham sido os fatores que conduziram a este resultado

Palavras-chave: Elegtromiografia; Força muscular; Quadriceps
1 Universidade Federal de Minas Gerais. Belo Horizonte, MG. Brasil.

Received: May 17, 2019 Accepted: December 20, 2019

How to cite this article Tourino FD, Lacerda LT, Andrade AGP, Diniz RCR, Chagas MH, Lima FV. The effect of 10 weeks of strength training on the electromyographic response of quadriceps portions. Rev Bras Cineantropom Desempenho Hum 2020, 22:e65225. D0l: http://dx.doi. org/10.1590/1980-0037.2020v22e65225

Copyright: This work is licensed under a Creative Commons Attribution 4.0 International License. 


\section{INTRODUCTION}

Force production in knee extension is a result of coordination of Vastus Medialis (VM), Vastus Lateralis (VL), Rectus Femoris (RF) and Vastus Intermedius $^{1}$, and is related to an adequate coordination ${ }^{2}$. Analysis of electromyographic (EMG) responses and activation ratio of these portions of the quadriceps may contribute to understanding the coordination in search for adequate training and rehabilitation strategies. Many researchers have studied activation of quadriceps applying different manipulations of protocols ${ }^{3-7}$. Sale ${ }^{8}$ suggests that an increase in quadriceps force would result in differentiated activations, and, besides, there are evidences that $\mathrm{RF}$ activation could be different from vastus ${ }^{9-11}$. Pincivero et al. ${ }^{3}$ analyzed EMG activity of VM, VL and RF at dynamic knee extension and verified distinct EMG responses. Rabita et al. ${ }^{4}$ verified RF increased activation and decrease activation of VM in five participants, and VL in two participants after 4 weeks of isometric training. Hatzel et al. ${ }^{5}$ verified that different repetition durations can result in different EMG responses, which suggests changes in coordination after different interventions.

Furthermore, Matheson et al. ${ }^{6}$ analyzed VM/VL activation ratio at distinct velocities $(180 \% \mathrm{~s}$ and $60 \% \mathrm{~s})$ and the results pointed out that the quadriceps have a different response to these velocities. Sczepanski et al. ${ }^{12}$ demonstrated higher VM/VL ratio at $120 \%$ s compared to $60 \%$ for concentric actions. Wong and $\mathrm{Ng}^{7}$ compared two protocols - 4 sets of 10 $\mathrm{RM}$ and 5 sets of $5 \mathrm{RM}$ - of squat and knee extension exercises during 8 weeks and the results demonstrated a similar increase in VM/VL ratio for both groups and in post-training VM activation occurred earlier than VL activation, which was not the case for pre-training.

Taking into account these differences, an analysis of chronic effects of strength training protocols with distinct muscle action durations on EMG of VM, RF and VL, would contribute to better understanding the neuromuscular responses and coordination. Therefore, the aim of the study was to analyse the effect of 10 weeks strength training with different muscle action durations on EMG amplitude and activation ratios of the quadriceps portions.

\section{METHOD}

Twenty three females aged from 18 to 30 years with no record of musculoskeletal injuries and with no strength training of lower limbs in the last six months volunteered for the study. The sample size was determined using GPower software and considering a probability of $20 \%$ dropout, the sample size was 24 volunteers. The effect size of 0.367 was calculated with $\eta^{2}=0.12$ extracted from RF muscle EMG activity data in 3 sets.

$1 \mathrm{RM}$ test in knee extension machine (Master Equipments ${ }^{\circledR}$ ) was used to assign the volunteers to one of the two groups. Committee on Ethics in Research (no 30594714.0.1001). The angle between the back support and 
the seat was set to $110^{\circ}$ and a fixing belt was placed next to the iliac crest of the participants. A linear potentiometer of $10 \mathrm{k} \Omega$ with linearity error of $2 \%$ and voltage range from $+10 \mathrm{~V}$ to $-10 \mathrm{~V}$ was attached to the rotation axis of the equipment to perform angle measurements.

Repeated measures procedure was adopted ${ }^{13}$, in which the volunteers were divided into two groups, and performed knee extension exercise 3 times per week during 10 weeks with 48 or 72 hours interval. For each subject the data were collected always at the same time of the day. At first, the participants were familiarized with the maximal voluntary isometric contraction (MVIC) test at $60^{\circ}$ knee flexion angle ${ }^{9}, 1 \mathrm{RM}$ and muscle action duration. MVIC familiarization consisted of two attempts during $3 \mathrm{~s}$ and 2 min interval between each attempt. The participants exerted maximal force against the arm of the machine, which remained fixed. An average of EMG signal peak values of each trial was registered. EMG and potentiometer data were synchronized and converted into digital signals using 14 bit A/D interface with -5 to +5 volt input (BIOVISION, Germany), and transmitted to laptop. 1RM test was performed $10 \mathrm{~min}$ after MVIC test and followed the guidelines of Diniz et al. ${ }^{14}$. The participants initiated the test at $100^{\circ}$ knee flexion and the load was gradually increased until it was not possible to reach $30^{\circ}$ knee flexion $\left(0^{\circ}=\right.$ extended knee $)$ in concentric action.

The participants performed 3 training sessions per week with 3 sets on the 1 st and 2 nd week, 4 sets at the $3 \mathrm{~d}$ and 4 th week, and 5 sets on the 5 th to 10 th week with 6 repetitions at $50 \%$ of $1 \mathrm{RM}$, and 3 min interval between the sets; the groups had different muscle action durations: (3:3) 3s CON and 3s ECC; (5:1) 5s CON and 1s ECC. These durations are the same as in the work of Goto et al. ${ }^{15}$, and protocols are within the values recommended for muscle hypertrophy ${ }^{16} .1 \mathrm{RM}$ test was repeated each two weeks to adjust the weight for the relative intensity ${ }^{17}$. MVIC tests and EMG data were collected during the execution of the protocols on the 2nd training session and on the last session. A metronome was used and in case the subject could not maintain the duration or complete the ROM, the set was interrupted.

Bipolar surface electrodes $\mathrm{Ag} / \mathrm{AgCl}$ with capture area of approximately $1 \mathrm{~cm}^{2}$ were placed at centre-to-centre distance of $2 \mathrm{~cm}$ along the muscle fibre direction of VM, VL and RF on the right leg of the participants ${ }^{18}$, according the recommendations of the European organization Surface Electromyography for the Non-Invasive Assessment of Muscles ${ }^{19}$. The signal was amplified 1000 times and was collected and processed using DASYLAB 11.0, Ireland, software at $2000 \mathrm{~Hz}$ sampling rate. The potentiometer signal was filtered using $2^{\text {nd }}$ order $10 \mathrm{~Hz}$ low-pass Butterworth filter. EMG signals collected during MVIC tests were processed with $2^{\text {nd }}$ order low-pass Butterworth filter $(20-500 \mathrm{~Hz})$ and full-wave rectified. To normalize the signal, EMG data of each muscle during the 3s of each MVIC were first smoothed using the average in sliding windows for each set of 40 data (20 $\mathrm{ms})^{20}$. Subsequently, the Root Mean Square (RMS) was calculated in a single window of $1 \mathrm{~s}$, being $0.5 \mathrm{~s}$ before and after the activation peak ${ }^{21}$ for 
each part. Mean value of two attempts was calculated and represented a MVIC value used to normalize the EMG signal obtained during training sessions. In this manner, to obtain an approximate EMG value in one repetition, EMG data from each muscle action (concentric and eccentric) in training sessions numbers 3 and 33 were first submitted to RMS calculation, and then an average signal between the concentric and eccentric actions of each repetition was calculated. Subsequently, to normalize the data, EMG signal of each repetition was divided by MVIC value in their respective protocols. The sets 4 and 5 of the last session were discarded to assure the same configuration for pre- and post-training conditions.

At first, a descriptive analysis of data, Shapiro-Wilk test of normality and Levene's homogeneity of variances test were performed. Mean of EMG data in each group for each repetition from 1st to 18th (total number of repetitions in 3 sets of 6 repetitions) was calculated for pre- and posttraining. Mean value of each repetition in pre-training was compared to the mean value of the equivalent repetition in post-training using twoway repeated measures ANOVA (factors: 1- Time and 2- Repetition). The data were expressed as mean and standard deviation. Activation and activation ratio variables were compared within the group. This was done for each muscle and in each group. Subsequently, EMG activation ratios (VM/VL; VM/RF and VL/RF) were calculated for each repetition in pre- and post-training conditions. Mean value of each activation ratio in each repetition in pre-training was compared to the mean value of the equivalent repetition in post-training using two-way repeated measures ANOVA (factors: 1- Time and 2- Repetition). To identify the differences between the equivalent repetitions for activation and activation ratio variables, Bonferroni post-hoc test was applied. For each ANOVA eta square $\left(\eta^{2}\right)$ was calculated for each factor, considering $\eta^{2}=0.140$ as high, $\eta^{2}=0.060$ as average, and $\eta^{2}=0.010$ as small ${ }^{22}$. The significance level was set to 0.05 , and the statistical package used was SPSS. 22.0.

\section{RESULTS}

Student's $t$-test revealed a significant increase in 1RM result in both groups (Fig. 1), after 10 weeks of training.

ANOVA revealed time $\mathrm{x}$ repetition interaction for $\mathrm{VM}(\mathrm{F} 1,35=1,882$; Power $\left.=0,956 ; \eta^{2}=0,02 ; p=0,022\right)$ and $\operatorname{RF}\left(F_{1,35}=2,099 ;\right.$ Power = 0,975; $\left.\eta^{2}=0,02 ; p=0,009\right)$. Bonferroni post-hoc test indicated a decrease in activation between the equivalent repetitions on the second half of each set for VM (Fig. 2b), and at the end of the $3 \mathrm{~d}$ set for RF (Fig. 2a). For VL $\left(F_{1,35}=1,563 ;\right.$ Power $\left.=0,901 ; \eta^{2}=0,02 ; p=0,078\right)$ the interaction was not confirmed. Main effect of time $\left(F_{1,35}=7,64\right.$; Power $=0,712 ; \eta^{2}=0,28 ; p$ $=0,018)$ and repetition $\left(F_{1,35}=65,92 ; p=0,001\right.$; Power $\left.=0,999 ; \eta^{2}=0,72\right)$ was identified for VM. Main effect of repetition was also identified for $\mathrm{RF}\left(\mathrm{F}_{1,35}=58,616\right.$; Power $\left.>0,999 ; \eta^{2}=0,84 ; p<0,001\right)$ and $\mathrm{VL}\left(\mathrm{F}_{1,35}=\right.$ 56,210; Power $\left.>0,999 ; \eta^{2}=0,84 ; p<0,001\right)$. 


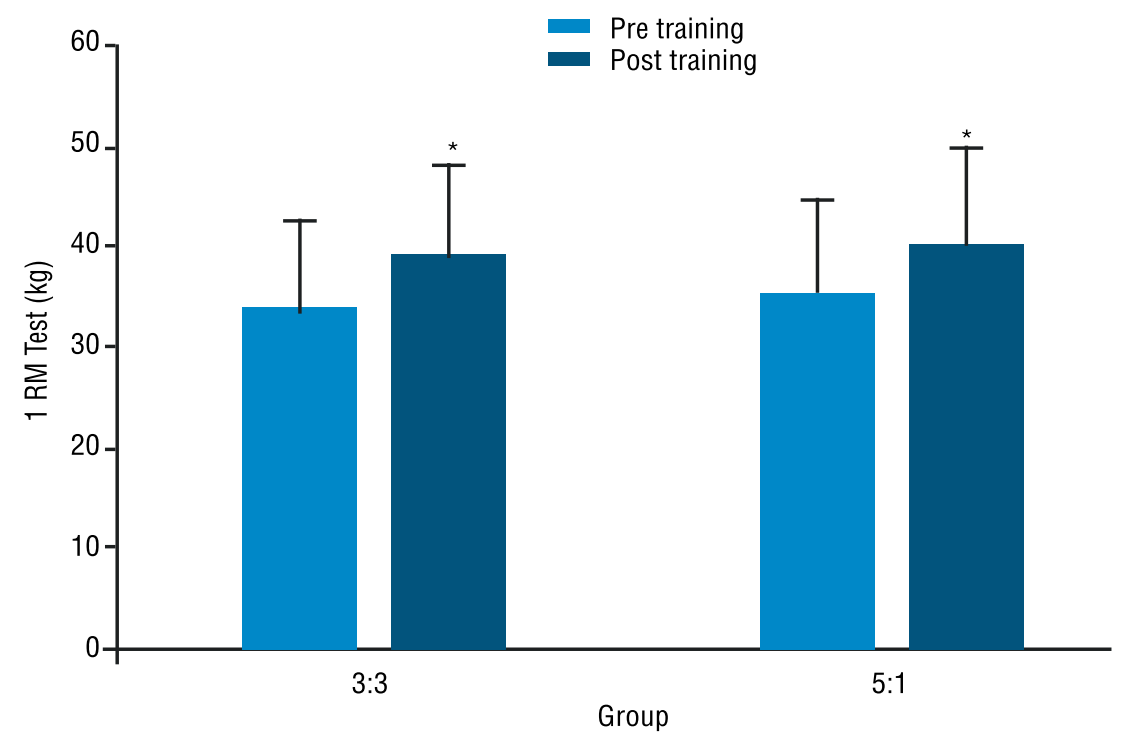

Figure 1. Performance in 1RM test.

${ }^{*}$ Post training greater than pre training - mean. SD. P<0,05

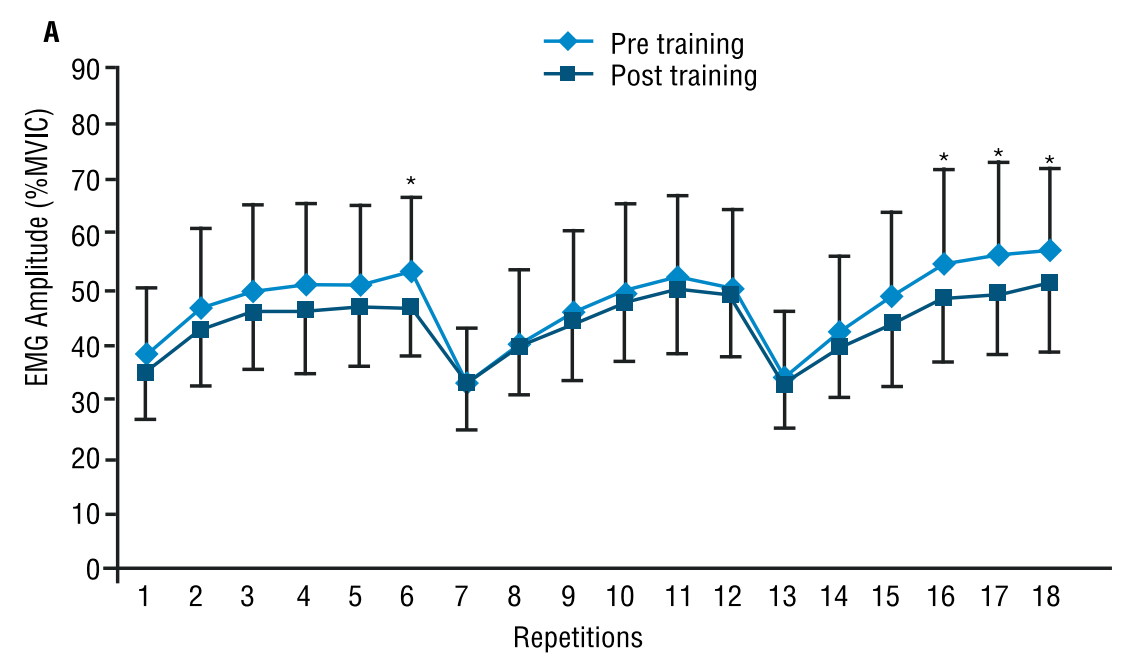

Figure 2. RF (a), VL (b) EMG responses - pre and post training (Group 3:3).

*Pre-training differs from post-training - mean. SD $P<0,05$ 
Two-way ANOVA showed significant interaction effects (Time $\mathrm{x}$ Repetition) for VM/RF ( $F_{1,35}=2,110$; Power $\left.=0,976 ; \eta^{2}=0,17 ; \mathrm{p}<0,01\right)$ and VM/VL $\left(\mathrm{F}_{1,35}=2,478\right.$; Power $\left.=0,992 ; \eta^{2}=0,31 ; \mathrm{p}<0,01\right)$ ratios. Bonferroni post-hoc test showed differences in $\mathrm{VM} / \mathrm{VL}$ ratio for the last three equivalent repetitions of the 2 nd set (Fig. 3a), while for VM/RF ratio the differences were detected for almost all equivalent repetitions of the 2 nd set (Fig. $3 \mathrm{~b}$ ). This result indicates change in coordination in the equivalent repetitions only in the 2 nd set. For VL/RF ratio the effect of interaction of these factors was not confirmed $\left(\mathrm{F}_{1,35}=0,956\right.$; Power $=$ 0,$654 ; \eta^{2}=0,32 ; p=0,510$ ).

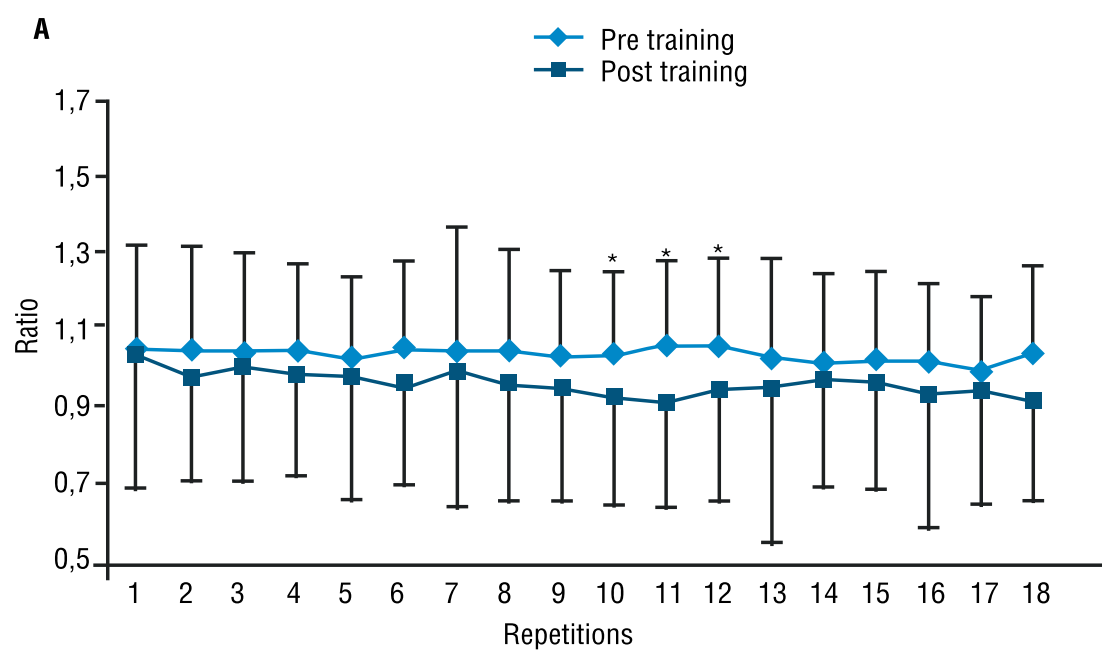

B

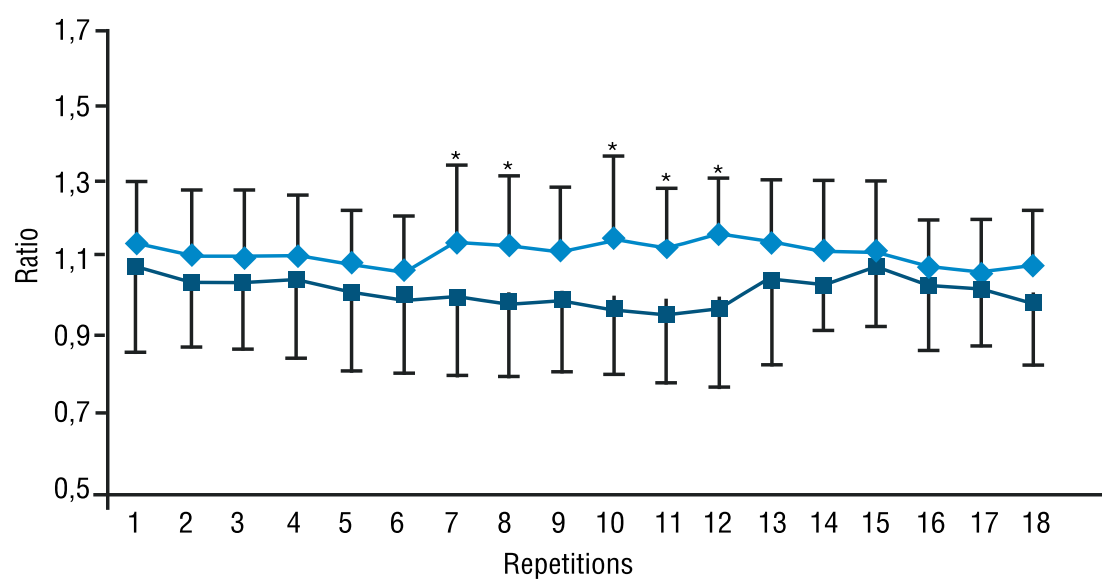

Figure 3. Comparison of VM/VL (a) and VM/RF (b) ratios between pre and post training. *Pre-training differs from post-training (Group 3:3) - mean. SD. P<0,05

Two-way ANOVA showed significant interaction effect between time and repetition for $\mathrm{RF}\left(\mathrm{F}_{1,35}=4,05\right.$; Power $\left.=0,999 ; \eta^{2}=0,05 ; \mathrm{p}<0,001\right), \mathrm{VL}$ $\left(\mathrm{F}_{1,35}=8,01 ;\right.$ Power $\left.=0,999 ; \eta^{2}=0,08 ; \mathrm{p}<0,001\right)$ and VM $\left(\mathrm{F}_{1,35}=4,15\right.$; Power $\left.>0,999 ; \eta^{2}=0,09 ; p<0,001\right)$. Bonferroni post-hoc test showed differences in equivalent repetitions (pre-/post-training) on second half of the sets, with activation decrease in all these repetitions for RF and VL (Fig. $4 \mathrm{a}$ and b). VM showed differences only in the last repetitions of the 
1 st set, and in last two repetitions of the $3 \mathrm{~d}$ set (Fig. 4c). Besides, main effect of time $\left(F_{1,35}=7,53\right.$; Power $\left.=0,705 ; \eta^{2}=0,26 ; p=0,019\right)$ and repetition $\left(\mathrm{F}_{1,35}=52,28\right.$; Power $\left.=0,999 ; \eta^{2}=0,66 ; \mathrm{p}<0,001\right)$ was observed for $\mathrm{VL}$, and of repetition for VM $\left(\mathrm{F}_{1,35}=28,56\right.$; Power $=0,999 ; \eta^{2}=0,8 ; \mathrm{p}<$ $0,001)$ and $\operatorname{RF}\left(\mathrm{F}_{1,35}=47,32 ;\right.$ Power $\left.=0,999 ; \eta^{2}=0,72 ; \mathrm{p}<0,001\right)$.
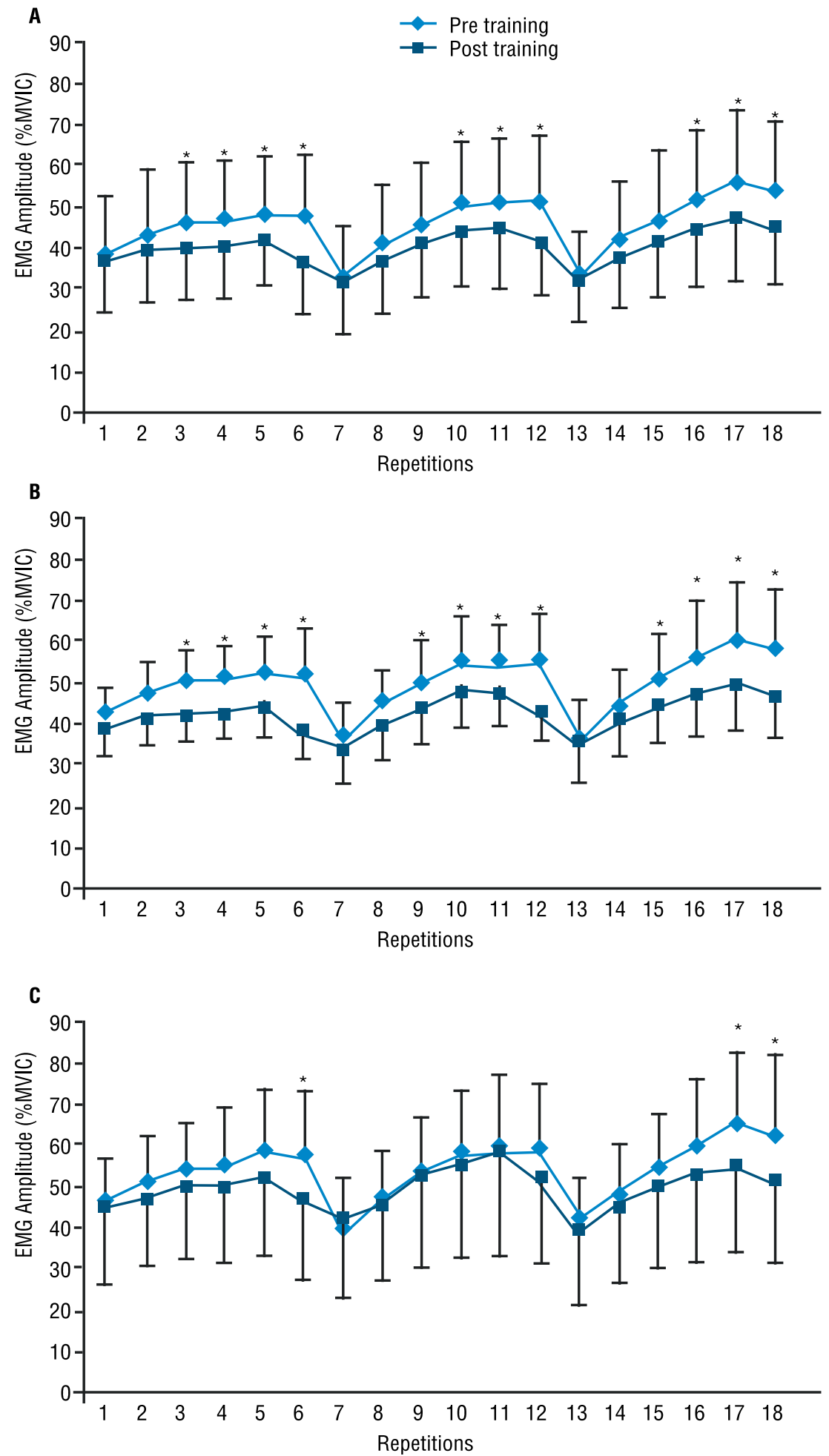

Figure 4. RF (a), VL (b) and VM (c) EMG responses - pre and post training (Group 5:1). *Pre-training differs from post-training (Group 3:3) - mean. SD. P<0,05 
Two-way ANOVA showed significant interaction (Time $\mathrm{x}$ Repetition) for VM/RF ratio $\left(F_{1,35}=2,186\right.$; Power $\left.=0,981 ; \eta^{2}=0,46 ; p<0,01\right)$, but Bonferroni post-hoc test did not indicate the differences between the equivalent repetition pairs. This result suggests that there were no changes in the $\mathrm{VM} / \mathrm{RF}$ ratio in the equivalent repetitions of each set after the experimental period. There was no interaction effect for $\mathrm{VM} / \mathrm{VL}$ ratio $\left(\mathrm{F}_{1,35}=1,533\right.$; Power $\left.=0,894 ; \eta^{2}=0,19 ; p=0,087\right)$ and $\mathrm{VL} / \mathrm{RF}\left(\mathrm{F}_{1,35}=\right.$ 1,241 ; Power $\left.=0,798 ; \eta^{2}=0,40 ; p=0,237\right)$, i.e, these coordination were not altered in the equivalent repetitions of the sets.

\section{DISCUSSION}

The study analyzed the effect of 10 weeks of strength training on EMG of VM, RF and VL. The 5:1 protocol resulted in decreasing EMG activity of $\mathrm{VL}$ and $\mathrm{RF}$ in the second half of both sets. Activation of VM was not influenced by training, as changes appeared only in three repetitions. In 3:3 protocol there was a decrease in VM activation in final equivalent repetitions of each set. RF had shown differences in the second half of the 3rd set, and no differences were observed for VL.

Despite the same time under tension, different duration of muscle actions result in different average velocities and different accelerations. Longer duration (5s) in concentric action results in a lower velocity, and, possibly, less variation of the velocity along the ROM, and a lower duration (1s) of the eccentric action may demand a higher force to slow down the external resistance $^{23}$. These differences cannot be identified with the same magnitude at the 3:3 protocol. Taking all these factors into account, changes in EMG may be expected ${ }^{5,24}$. Considering different muscle lengths and volumes, insertion angles, and fibre positioning of $\mathrm{VM}, \mathrm{VL}, \mathrm{RF}$, one of which is biarticular $(\mathrm{RF})$, distinct activation responses are not unusual, if there is a change of external resistance acceleration demand in strength exercise ${ }^{25}$.

Decrease in activation was not detected in all portions and this seems to contrast the expected decrease as a function of increasing force and possible hypertrophy. The training period lasted 10 weeks but shorter periods may result in muscle hypertrophy ${ }^{25}$, and this might contribute to lower motor unit $(\mathrm{MU})$ recruitment in response to the same relative force demand, since increase in muscle fibre cross section increases its force production capacity. The sample used here is a part of a larger study in which the hypertrophy was observed by magnetic resonance. The cross-sectional area increased in $5: 1$ group, RF by $6,78 \%$, VL by $5,10 \%$, and VM by $6,47 \%$. In 3:3 group, RF increased by $3,35 \%$, VL by $4,83 \%$, and VM by 7,31\%.

Training load progression depended only on volume increase (from 3 to 5 sets along de period) at submaximal intensity (50\% of $1 \mathrm{RM})$. However, it is known that untrained participants support concomitant increases of volume and intensity at the initial stages of training and this is referred to as overload training principle. Following this principle the relative percentage of maximal force needs to be exceeded with time in order to continue training 
responses. However, with a proven gain in muscle force and hypertrophy, the same intensity maintained during the last sets of the experimental period might represent a reduced demand in post-training conditions, which can be verified by decrease in EMG activity. The training and tests were performed at submaximal intensity, however, studies with higher intensities might produce different results. Duchateau et al. ${ }^{26}$ demonstrated that under maximal force requirement an increase in EMG is explained by recruitment of larger number of MU accompanied by increased synchronization of these units. Similarly, with a same intensity percentage (submaximal effort), there would be a recruitment of reduced number of $\mathrm{MU}$, due to a better synchronization to produce the same relative force after the training period 26. Franke et al. ${ }^{10}$ used maximal eccentric and isometric actions and demonstrated an increase in $\mathrm{VM}$ activation after 12 weeks of eccentric training at the velocity of $60 \%$, whilst VL did not show a difference in EMG activity. However, these authors used a protocol with faster eccentric actions $(\sim 1 \mathrm{~s})$, higher relative intensity (maximal), and greater number of repetitions ${ }^{12}$.

Despite using the belt to fix the participants on the machine, some slight changes in hip position might have occurred, which could have influenced the RF response. However, this cannot be confirmed with the methodology used in this study.

No changes were observed in activation ratios in 5:1 protocol when the equivalent repetitions were compared. Despite the decrease in activation, it is possible that this decrease was of similar magnitude for them, and therefore coordination was preserved.

Differences in 3:3 protocol for VM/VL and VM/RF ratios were found only for the second set (FIG. 4). For VM/VL ratio, it occurred in three repetitions at the end of the set, and then the results returned to the previous values. For VM/RF ratio the change occurred in five repetitions. Yet, despite some changes in the EMG in post-training, it appears that the ratios changed very little between the equivalent repetitions. The monoarticular pattern of the exercise with limited degrees of freedom might have been a restricting factor for changing the ratios.

EMG activity depends on multiple factors, such as length of the muscle, number of the joints involved in the exercise ${ }^{27-29}$, configuration of the training load ${ }^{6,30}$ and subject's training status. Under a high force requirement the neuromuscular system would demand a recruitment of MU close to maximal, however, for the submaximal efforts it is possible that this recruitment occurs in a different manner, depending on the situation and even on the subject, with the purpose of maintaining the efficiency of the task.

In untrained individuals the action potential firing pattern is asynchronous and the coordination between the muscles might variate along the time ${ }^{26}$. This study was performed with untrained participants and, in this case, it is believed that EMG analysis of the sequence of concentric and eccentric muscle actions might have registered data with considerable variation. However, these arguments do not seem to be sufficient to explain the fact that using the methodology adopted the differences in the ratios 
appear only in the 2 nd set of the 3:3 protocol. Taking into account the volume of the compared data, these small differences might support the idea that a limited degree of freedom of the knee extension machine, and the moderate training load contributed to the small changes in the muscle coordination observed.

\section{CONCLUSION}

The results allow concluding that EMG responses in equivalent repetitions of 3 sets of knee extension exercise after 10 weeks of training are not homogeneous between the quadriceps portions. Muscle activation decreased in equivalent repetitions at the second half of the sets; however, these changes did not affect in a consistent manner the coordination of quadriceps activation. This might be the result of limited degrees of freedom, and the adopted training load progression. Additional studies are suggested with different progression of the training load along the experiment, especially with a sharp increase in intensity, and use of other mono and multiarticular exercises.

\section{COMPLIANCE WITH ETHICAL STANDARDS}

\section{Funding}

This research did not receive any specific grant from funding agencies in the public, commercial, or not-for-profit sectors.

\section{Ethical approval}

Ethical approval was obtained from the local Human Research Ethics Committee -(Universidade Federal de Minas Gerais) and the protocol (no. 30594714.0.1001) was written in accordance with the standards set by the Declaration of Helsinki.

\section{Conflict of interest statement}

The authors have no conflict of interests to declare.

\section{Author Contributions}

Conceived and designed the experiments: FDT, RCRD, MHC, FVL. Performed the experiments: FDT, LTL, RCRD. Analyzed the data: FDT, LTL, AGPA, RCRD, FVL. Contributed reagents/materials/analysis tools: Wrote the paper: FDT, MHC, FVL

\section{REFERENCES}

1. Kristiansen M., Madeleine P., Hansen EA., Samani A. Inter-subject variability of muscle synergies during bench press in Power lifters and untrained individuals. Scand J Med Sci Sports 2015;25:89-97.

2. Prilutsky B.I. Coordination of Two- and One-Joint Muscles: Functional Consequences and Implications for Motor Control. Motor Control 2000;4:97-116. 
3. Pincivero DM, Gandhi V, Timmons MK, Coelho AJ. Quadriceps femoris electromyogram during concentric, isometric and eccentric phases of fatiguing dynamic knee extensions. J Biomech 2006;39:246-254

4. Rabita G, Perot C, Lensel-Corbeil G. Differential effect of knee extension isometric training on the different muscles of the quadriceps femoris humans. Eur J Appl Physiol 2000;83:531-538.

5. Hatzel BM, Stephen CG, Scott J, Heather S. Effects of Lift Velocity on Muscle Activation During Leg Extension. Open J Sports Med 2012;6:42-47.

6. Matheson JW, Kernozek TW, Fater, DC, Davies GJ. Electromyographic activity and applied load during seated quadriceps exercises. Med Sci Sports Exerc 2001;10:1713-1725.

7. Wong YM, Ng G. Resistance training alters the sensorimotor control of vasti muscles. J Electromyogr Kinesiol 2000;20:180-184.

8. Sale DG. Neural adaptation to strength training In: Komi PA, organizer. Strength and Power in Sport. London: Ed. Blackwell Science; 2003. p. 249-265.

9. Pincivero DM, Coelho AJ, Campy RM. Quadriceps Femoris Activation: Influence of Contraction Intensity on Neurobehaviour. In: Herzog W, organizer. Skeletal Muscle Mechanics: From Mechanisms to Function. Chichester: Ed. John Wiley \& Sons; 2000. p. 391-408.

10. Franke RA, Baroni BM, Rodrigues R, Geremia JM, Lanferdini FJ, Vaz MA. Neural and morphological adaptations of vastus lateralis and vastus medialis muscles to isokinetic eccentric training. Motriz: Rev Educ Fís 2014;3:317-324.

11. Santtila M, Kyröläinen H, Häkkinen K. Changes in maximal and explosive strength, electromyography, and muscle thickness of lower and upper extremities induced by combined streng th and endurance training in soldiers. J Strength Cond Res 2009;23:1300-1308.

12. Sczepanski TL, Gross MT, Duncan PW, Chandler JM. Effect of contraction type, angular velocity, and arc of motion on VM: VL EMG ratio. J Orthop Sport Phys 1991;14:256-262.

13. Dancey CP, Reidy J. Estatística sem matemática para psicologia. Porto Alegre: Artmed; 2006.

14. Diniz, RCR, Martins-Costa HC, Machado SC, Lima FV, Chagas MH. Repetition duration influences ratings of perceived exertion. Percept Mot Skills 2014;1:261-273.

15. Goto K, Ishii N, Kizuka T, Kraemer RR, Honda Y, Takamatsu K. Hormonal and metabolic responses to slow movement resistance exercise with different durations of concentric and eccentric actions. Eur J Appl Physiol 2009;5:731-739.

16. Wernbom M, Augustsson J, Thomeé H. The influence of frequency, intensity, volume and mode of strength training on whole muscle cross-sectional area in humans. Sports Med 2007;37:225-264.

17. Ema R, Wahahara T, Miyamoto, N, Kanehisa H, Kawakami Y. Inhomogeneous architectural changes of the quadriceps femoris induced by resistance training. Eur J Appl Physiol 2013;2691-703.

18. Merletti R, Parker PA. Electromyography: physiology, engineering, and noninvasive applications. New Jersey: John Wiley \& Sons; 2004.

19. Surface Electromiography for the Non-Invasive Assessmente of Muscle. Available from <http://www.seniam.org> [2015 March 9].

20. Ekstrom RA, Osborn RW, Goehner HM, Moen AC, Ommen BM, Mefferd MJ. et al. Electromyographic normalization procedures for determining exercise intensity of closed chain exercises for strengthening the quadriceps femoris muscles. J Strength Cond Res 2012;3:766-71.

21. Andersen LL, Magnusson SP, Nielsen M, Haleem J, Poulsen K, Aagaard P. Neuromuscular Activation in Conventional Therapeutic Exercises and Heavy Resistance Exercise: Implications for Rehabilitation. Phys Ther 2006;683-97.

22. Cohen J. Statistical power analysis for the behavioral sciences. New Jersey: Lawrence Earlbaum Associates; 1988. 
23. Sampson JA, Donohoe A, Groeller H. Effect of concentric and eccentric velocity during heavy-load non-ballistic elbow flexion resistance exercise. J Sci Med Sport 2014;17:306-311.

24. Martins-Costa HC, Diniz RCR, Lima FV, Machado SC, Almeidda RSVD, Andrade AGPD, et al. Longer repetition duration increases muscle activation and blood lactate response in matched resistance training protocols. Motriz: Rev Educ Fís 2016;1:35-41.

25. Earp JE, Newton RU, Cormie P, Blazevich AJ. Inhomogeneous Quadriceps Femoris Hypertrophy in Response to Strength and Power Training. Med Sci Sports Exerc 2015;47:2389- 2397. 26

26. Duchateau J, Semmler JG, Enoka RM. Training adaptations in the behavior of human motor units. J Appl Physiol 2006;6:1766-1775. 30

27. Yamashita N. EMG activities in mono-and bi-articular thigh muscles in combined hip and knee extension. Eur J Appl Physiol Occup Physiol 1988;58:274-277.

28. Signorile JF, Weber B, Roll B, Caruso JF, Lowensteyn I, Perry A.C. An electroyographical comparison of the squat and knee extension exercises. J Strength Cond Res 1994;8:178-183.

29. Wright GA, Delong TH, Gehlsen G. Electromyographic Activity of the Hamstrings During Performance of the Leg Curl, Stiff-Leg Deadlift, and Back Squat Movements. J Strength Cond Res 1999;13:168-174.

30. Ribeiro DC, Loss JF, Cañeiro JPT, Lima CS, Martinez FG. Electromyographical analysis of the quadriceps during knee extension at different speeds. Acta Ortop Bras 2005;13:189-193.

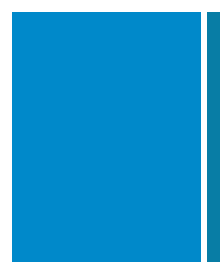

Corresponding author

Fernando Vitor Lima

Federal University of Minas Gerais

Weight training laboratory

Av. Presidente Antônio Carlos 6627

Belo Horizonte - MG

Phone: +55 31999567005

E-mail address: ferlima@eeffto.ufmg.br 